\title{
A wearable microwave detector for diagnosing thoracic injuries-test on a porcine pneumothorax model
}

\author{
Nils Petter Oveland ${ }^{1,2,3^{*}}$, Ruben Buendia ${ }^{4,5,6}$, Bengt Arne Sjöqvist ${ }^{4,5,6}$, Marianne Oropeza-Moe ${ }^{7}$, \\ Nina Gjerde Andersen ${ }^{2}$, Andreas Fhager ${ }^{4,5}$, Mikael Persson ${ }^{4,5}$, Mikael Elam ${ }^{5,8}$, Stefan Candefjord $4,5,6$ \\ From London Trauma Conference 2014 \\ London, UK. 9-12 December 2014
}

\section{Background}

In the prehospital setting, a point-of-care diagnostic test is needed to diagnose pneumothorax (PTX) and monitor its progression to prevent unnecessary patient morbidity and mortality. Ultrasonography is more sensitive than supine chest $\mathrm{x}$-ray for diagnosing PTX, but the accuracy depends on the experience of the operator. Therefore, a non-operator dependent instrument would be valuable for detection and continuous monitoring of an evolving PTX.

\section{Study objective}

To evaluate the potential of a new microwave technology for diagnosing PTX.

\section{Methods}

An experimental PTX model was set up in two anesthetized pigs. A belt with eight microwave antennas was strapped around the pig's chest. Air was insufflated into a catheter in the right pleural space in twelve incremental steps (PTX volumes: 50, 100, 150, 200, 250, 300, 400, 500, 750, 1000, 1500, $2000 \mathrm{~mL}$ ). Each injection was followed by a measurement with the microwave detector. A computer-based classification algorithm was used to distinguish between the measurements using a leave-one-out approach (i.e. the sample to be classified was not included in the training data matrix), where each PTX volume was treated as an individual class.

\footnotetext{
* Correspondence: nils.petter.oveland@me.com

'Department of Health Studies, Network for Medical Sciences, University of Stavanger, Stavanger, Norway.

Full list of author information is available at the end of the article
}

\section{Results}

The microwave belt was able to differentiate between normal lungs and PTX in both animals with an overall diagnostic accuracy of $100 \%$ (i.e. a sensitivity and specificity of 100\%). Furthermore, the classification accuracy for predicting the size of PTX was 100\% and $98 \%$ for each pig, respectively.

\section{Conclusion}

The microwave technology proved promising in diagnosing and predicting size of PTX ranging from $50 \mathrm{~mL}$ to $2000 \mathrm{~mL}$. This within-model experiment only differentiated PTX and normal lungs in individual pigs and not between different animals. A larger validation study needs to be done to further evaluate the diagnostic accuracy of the microwave detector.

\section{Institution}

This preliminary study was conducted at Sandnes Education and Research Center Høyland (SEARCH), Sandnes, Norway.

\footnotetext{
Conflict of interest

The authors state no conflicts of interest.

\section{Authors' details}

'Department of Health Studies, Network for Medical Sciences, University of Stavanger, Stavanger, Norway.. ${ }^{2}$ Department of Anesthesiology and Intensive Care, Stavanger University Hospital, Stavanger, Norway. ${ }^{3}$ Department of Research and Development, Norwegian Air Ambulance Foundation, Droebak, Norway. ${ }^{4}$ Chalmers University of Technology, Gothenburg, Sweden. ${ }^{5}$ MedTech West, Gothenburg, Sweden. ${ }^{6}$ SAFER Vehicle and Traffic Safety Centre at Chalmers University of Technology, Gothenburg, Sweden. ${ }^{7}$ Department of Production Animal Clinical Sciences, Faculty of Vetbio, Norwegian University of Life Sciences, Sandnes, Norway. ${ }^{8}$ Sahlgrenska University Hospital, Gothenburg, Sweden.
} 
Published: 11 September 2015

doi:10.1186/1757-7241-23-S2-A20

Cite this article as: Oveland et al: A wearable microwave detector for diagnosing thoracic injuries-test on a porcine pneumothorax model. Scandinavian Journal of Trauma, Resuscitation and Emergency Medicine 2015 23(Suppl 2):A20.

Submit your next manuscript to BioMed Central and take full advantage of:

- Convenient online submission

- Thorough peer review

- No space constraints or color figure charges

- Immediate publication on acceptance

- Inclusion in PubMed, CAS, Scopus and Google Scholar

- Research which is freely available for redistribution

Submit your manuscript at www.biomedcentral.com/submit

() Biomed Central 